\title{
Can athletes jump high while landing safely? Relationships between lower limb landing biomechanics and jump performance during a jump-landing task
}

\author{
AARON S. Fox* \\ Centre for Sport Research, School of Exercise and Nutrition Sciences, Deakin University
}

\begin{abstract}
Rapid jump-landing is an important performance determinant across sports. While the jump is important for performance, the preceding landing may expose athletes to anterior cruciate ligament (ACL) injury. 'Safe' landing techniques are promoted to minimise injury risk, however it is important that these are not detrimental to subsequent jumping performance. This study determined whether there is a relationship between biomechanical factors associated with ACL loading or injury risk and jump performance during a bilateral drop vertical jump. Thirty-two female sub-elite netball players had three-dimensional (3D) data recorded from a bilateral drop vertical jump task. 3D hip, knee and ankle joint rotations, 3D knee joint moments, and $3 D$ ground reaction forces (GRFs) were extracted from the landing phase of the task. Jump height, ground contact time and peak power output were extracted from the jumping phase of the task. One-dimensional statistical parametric mapping $(p<0.0011)$ was used to investigate the relationship between the landing and jumping phases. Greater knee internal rotation moments and higher GRFs during landing were associated with reduced jump height. Greater hip and knee flexion, reduced hip internal rotation and knee abduction, and a more dorsiflexed/less plantarflexed ankle position at initial contact during landing were associated with longer ground contact times. Certain biomechanical factors commonly targeted within ACL injury prevention programs were associated with both poorer and better jump performance. The links between landing technique and jumping performance suggest jump performance training should be considered in parallel with landing injury prevention programs.
\end{abstract}

\section{Introduction}

C Ertain sports require athletes to jump frequently during gameplay, sometimes in quick succession after landing [1, 2]. Performing subsequent maximal jumping efforts rapidly after landing is key to success in various scenarios, such as rebounding after contesting a shot in netball or performing multiple block jumps in volleyball. While the jumping effort is important for performance, landings that precede these jumps may expose athletes to risk of anterior cruciate ligament
(ACL) injury.

ACL injury prevention programs typically incorporate technique guidelines to promote a safer landing technique [3]. Programs incorporating technique guidelines revolving around performing soft landings with deep hip and knee flexion [4] and focusing on keeping the knee over the toe [5] have been effective in reducing ACL injury occurrences. Although effective in reducing ACL injury risk, these guidelines may be detrimental to jumping performance [6]. Dai et al. [6] observed that when athletes were instructed to 'land softly'

*Corresponding author: aaron.f@deakin.edu.au

This work is a preprint and has not yet been peer-reviewed.

All authors have read and approved this version of the manuscript for pre-print.

Aaron S. Fox (@aaron_s_fox) can be found on Twitter.

This work can be cited as: Fox AS (2019). 'Can athletes jump high while landing safely? Relationships between lower limb landing biomechanics and jump performance during a jump-landing task. SportR $\chi$ iv. doi: 10.31236/osf.io/gpfh9 
or 'land with greater knee flexion,' ground contact time increased and jump height decreased compared to their natural technique during a stop-jump task. Coach and athlete behaviour in sport is driven by performance, therefore injury prevention programs that are detrimental to performance are unlikely to be well-received and implemented [7].

The relationship between landing mechanics and subsequent jump performance has received little attention [6] in existing literature. Understanding the relationships between landing biomechanics and subsequent jump performance metrics can yield better insight for the design of targeted ACL injury prevention programs. Should deterimental relationships between 'safe' landing technique and jump performance exist, injury prevention programs may need to consider jump performance training in parallel to ensure the program does not impact performance. The aim of this study was to determine whether there is a relationship between biomechanical factors associated with ACL loading or injury risk and jump performance. It was hypothesised that biomechanical factors associated with reduced ACL loading or injury risk would be associated with poorer jumping performance.

\section{Methods}

\subsection{Participants}

Thirty-two female sub-elite netball players (age $=23.1 \pm 3.0$ years; height $=171.4 \pm 7.8 \mathrm{~cm}$; mass $=67.6 \pm 8.2 \mathrm{~kg}$ ) participated in this study. Players were free from current injury, had not suffered an injury to the lower back or limbs in six months, and had no history of lower back or limb surgery. Prior to data collection, a test-leg for the jump-landing protocol was determined by asking players to trial landing on each limb for a sport-specific landing task. The University's Human Research Ethics Committee approved the study and informed consent was obtained before data collection.

\subsection{Experimental Task}

Participants attended the laboratory for one testing session where they performed a drop vertical jump-landing protocol. The drop vertical jump-landing task was identical to that used in existing research [8]. Participants jumped from a $30 \mathrm{~cm}$ high box to a landing area at a distance $50 \%$ of their height from the box, and immediately rebounded for a maximal vertical jump[8]. Participants received task instructions, with an emphasis placed on jumping as high as they could after landing [8]. Five successful trials were collected and used for analysis, with 30 seconds rest between trials. A successful trial was characterised by: (i) jumping off both feet from the box; (ii) jumping forward, but not vertically to the landing area; (iii) landing with the foot of the test and opposite leg on and off the force plate, respectively; and (iv) completing the task in a fluid motion [8].

\subsection{Data Collection and Analysis}

Three-dimensional (3D) kinematics and kinetics of the lower limb were computed using an established musculoskeletal model[9]. An eight camera 3D motion capture system (Vicon, Oxford Metrics Limited, Oxford, United Kingdom) sampling at $250 \mathrm{~Hz}$, synchronised with a $600 \mathrm{~mm}$ by $900 \mathrm{~mm}$ in-ground force plate (Advanced Medical Technology Incorporated, Watertown, MA, United States) sampling at $1000 \mathrm{~Hz}$ collected marker trajectory and ground reaction force (GRF) data. Thirtytwo $14 \mathrm{~mm}$ reflective markers were attached to anatomical landmarks according to model specifications [9]. After marker placement, a two-second calibration trial was recorded with the participant standing in a stationary (neutral) position 9 .

Kinematic and GRF data were processed within Visual 3D software (C-Motion, Rockville, MD, United States). Marker trajectories and GRF data were low-pass filtered using a cubic smoothing spline with a cut-off 
frequency of $12 \mathrm{~Hz}$, determined from residual analysis of marker trajectory data and visual inspection of data filtered at varying frequencies. Hip, knee and ankle joint rotations were estimated from filtered marker trajectories and expressed relative to the participants' stationary (neutral) trial. Knee joint moments were obtained by submitting filtered kinematic and GRF data to a conventional inverse dynamics analysis. Joint moments $(\mathrm{Nm})$ were normalised to the participants' height $(\mathrm{m})$ and mass $(\mathrm{kg})$, were expressed in the reference frame of the respective joint coordinate system[10], and represent the external loads applied at each joint. Joint rotation and moment data were extracted from the period the participant was in contact with the ground, defined by the instance of initial contact (IC; vertical GRF first exceeding $10 \mathrm{~N}$ ) to take-off (TO; vertical GRF returning below $10 \mathrm{~N}$ ). This data was then divided into landing and jumping phases. The average 3D position of markers attached to the pelvis (i.e. mid-pelvis point) was calculated as a proxy for centre of mass motion and used to define the two phases. The landing phase was defined as the period from IC to the minimum vertical position of the mid-pelvis point, while the jumping phase as the period from the minimum vertical position of the mid-pelvis point to TO.

Jump performance metrics (jump height, ground contact time, peak power) were extracted from biomechanical data. The standing height of the mid-pelvis point during the participant's stationary trial was subtracted from the peak height of the mid-pelvis point to obtain total jump height. Ground contact time was calculated as the duration between IC and TO points. Whole-body power output was calculated based on each participants mass and the amount of mechanical work performed to move the mid-pelvis point in a vertical direction at each time step. Peak vertical power (normalised to body mass) was the maximum power achieved between the start of the jump phase and peak jump height.

\subsection{Statistical Analyses}

One-dimensional statistical parametric mapping (SPM1D) was used to investigate the relationship between landing biomechanics and jump performance. Canonical correlations analysis (CCA) [11] was used to examine the relationships between the jump performance metrics and (i) 3D hip, knee and ankle joint rotations; (ii) 3D knee joint moments; and (iii) 3D GRFs across the landing phase. Planned post-hoc analyses of joint rotation and moment, and GRF vector-field couples using CCA; and of the individual joint rotation and moment, and GRF components using SPM1D linear regression were also conducted. All joint rotation and moment, and GRF waveforms extracted from the landing phase were time-normalised to 101 data points (i.e. $0-100 \%$ of the landing phase) prior to analysis. To retain a Type I family-wise error rate of alpha $=0.05$, a corrected Sidak corrected threshold for statistical significance $(\alpha=0.0011)$ based on the total number of tests conducted was calculated[11].

To visualise the relationships between jump performance metrics and landing biomechanics, trials were split into tertiles (i.e. $0-33^{\text {rd }}$ percentile - 'low' performance; $33^{\text {rd }}-66^{\text {th }}$ percentile - 'moderate' performance; $66^{\text {th }}-100^{\text {th }}$ percentile - 'high' performance) based on the relative jump performance metric. Mean joint rotation, knee joint moments and ground reaction forces from the landing phase were calculated for trials in each tertile and plotted against one another.

\section{Results}

\subsection{Jump Height}

Figures one, two and three show mean joint rotations, knee joint moments and GRF data, respectively, for trials categorised as 'low,' 'moderate' and 'high' performance based on jump height. 

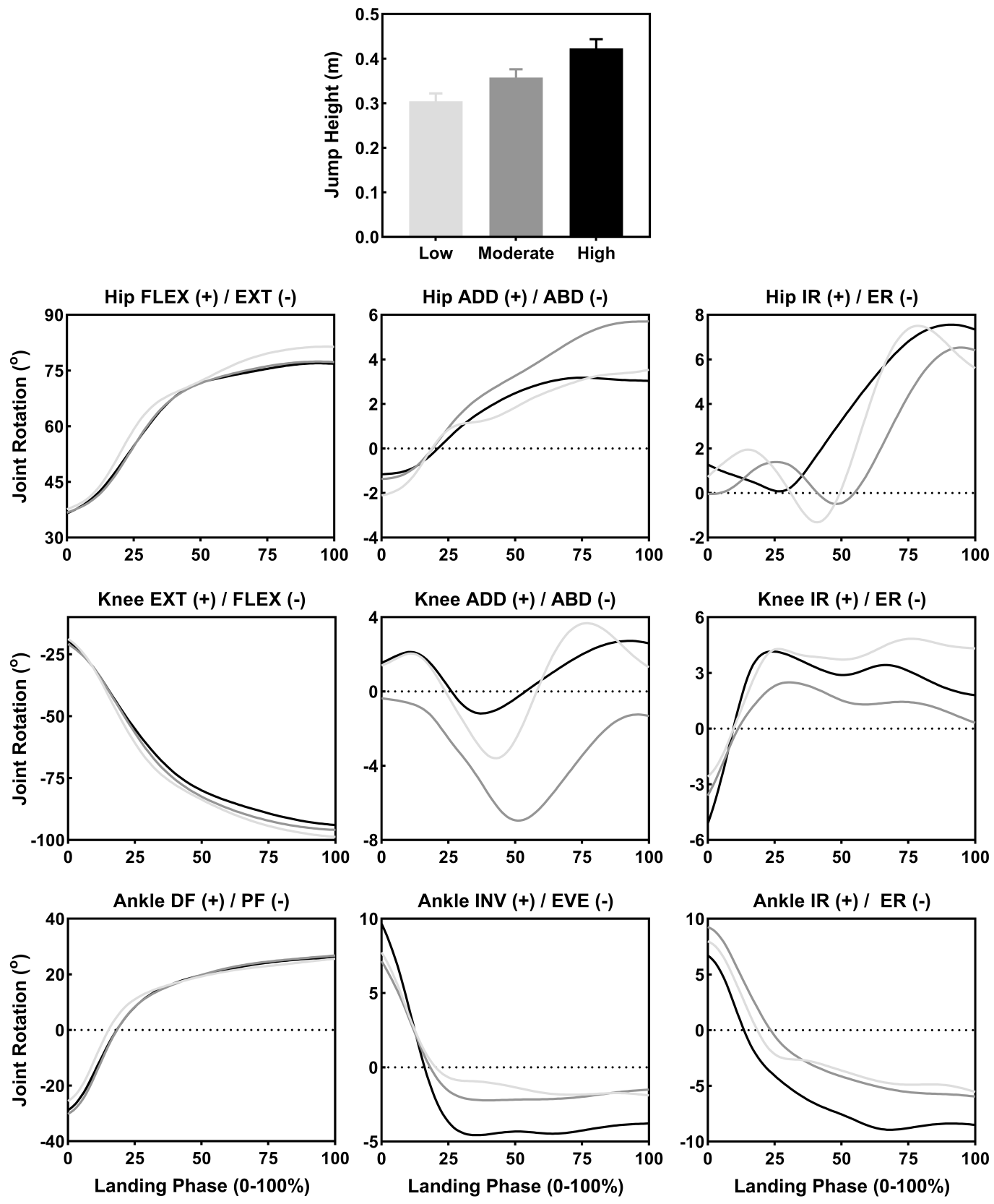

Figure 1: Mean hip, knee and ankle joint rotations across the landing phase for trials categorised as 'low' $(n=53)$, 'moderate' $(n=52)$ and 'high' $(n=55)$ performance based on jump height. FLEX - flexion; EXT-extension; $A D D$-adduction; $A B D$ - abduction; IR - internal rotation; ER - external rotation; DF - dorsiflexion; PF plantarflexion; INV - inversion; EVE - eversion.

\subsubsection{Joint Rotations}

No statistically significant relationships were identified between jump height and hip or knee 

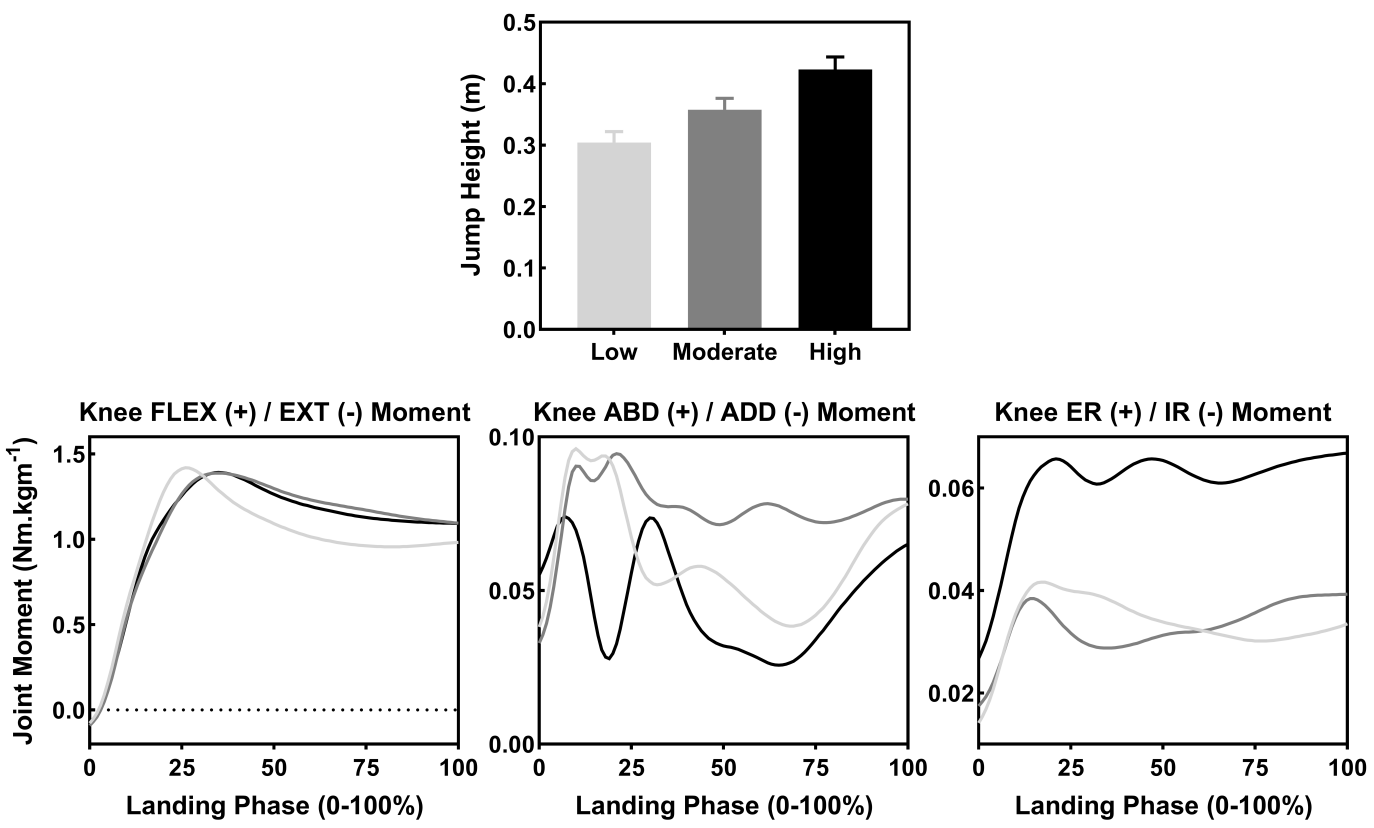

Figure 2: Mean knee joint moments across the landing phase for trials categorised as 'low' $(n=53)$, 'moderate' $(n=52)$ and 'high' $(n=55)$ performance based on jump height. FLEX - flexion; EXT-extension; ADD - adduction; $A B D$ - abduction; IR - internal rotation; ER - external rotation.

joint rotations. A statistically significant relationship was observed between jump height and $3 \mathrm{D}$ ankle joint rotations at $0-23 \%(\mathrm{p}=$ $0.0002)$ and $37-99 \%(\mathrm{p}<0.0001)$ of the landing phase. Post-hoc analyses revealed statistically significant relationships between the sagittal-transverse ankle joint rotation vectorfield couple at $8-24 \%(\mathrm{p}=0.0004)$ and $35-100 \%$ $(\mathrm{p}<0.0001)$; and the frontal-transverse ankle joint rotation vector-field couple at $6-14 \%(\mathrm{p}=$ $0.0009)$ and $34-100 \%(\mathrm{p}<0.0001)$ of the landing phase. Greater ankle eversion at $33-100 \%$ of the landing phase was associated with a greater jump height $(p<0.0001)$ (see Figure 1$)$.

\subsubsection{Knee Joint Moments}

A statistically significant relationship was observed between jump height and 3D knee joint moments at $18-23 \%(\mathrm{p}=0.001)$ and $41-62 \%(\mathrm{p}<$ 0.0001 ) of the landing phase. Post-hoc analyses revealed a statistically significant relationship between the sagittal-transverse knee joint moment vector-field couple at $21-23 \%(\mathrm{p}=0.0011)$ and $39-93 \%(\mathrm{p}<0.0001)$ of the landing phase. A greater knee internal rotation moment at 77$91 \%$ of the landing phase was associated with greater jump height $(p=0.0006)$ (see Figure 2).

\subsubsection{Ground Reaction Forces (GRFs)}

A statistically significant relationship was observed between jump height and 3D GRFs at $27-32 \%(\mathrm{p}=0.0007)$ and $57-100 \%(\mathrm{p}<$ 0.0001) of the landing phase. Post-hoc analyses revealed statistically significant relationships between the anterior/posterior-medial/lateral GRF vector-field couple at $26-31 \%(p=0.0008)$; the anterior/posterior-vertical GRF vector-field couple at $27-33 \%(\mathrm{p}=0.0004)$ and $63-91 \%(\mathrm{p}$ $<0.0001$ ); and the medial/lateral-vertical GRF vector-field couple at $13-16 \%(\mathrm{p}=0.001)$ and $55-100 \%(\mathrm{p}<0.0001)$ of the landing phase. Reduced posterior GRF at $27-31 \%(\mathrm{p}=0.0007)$, 


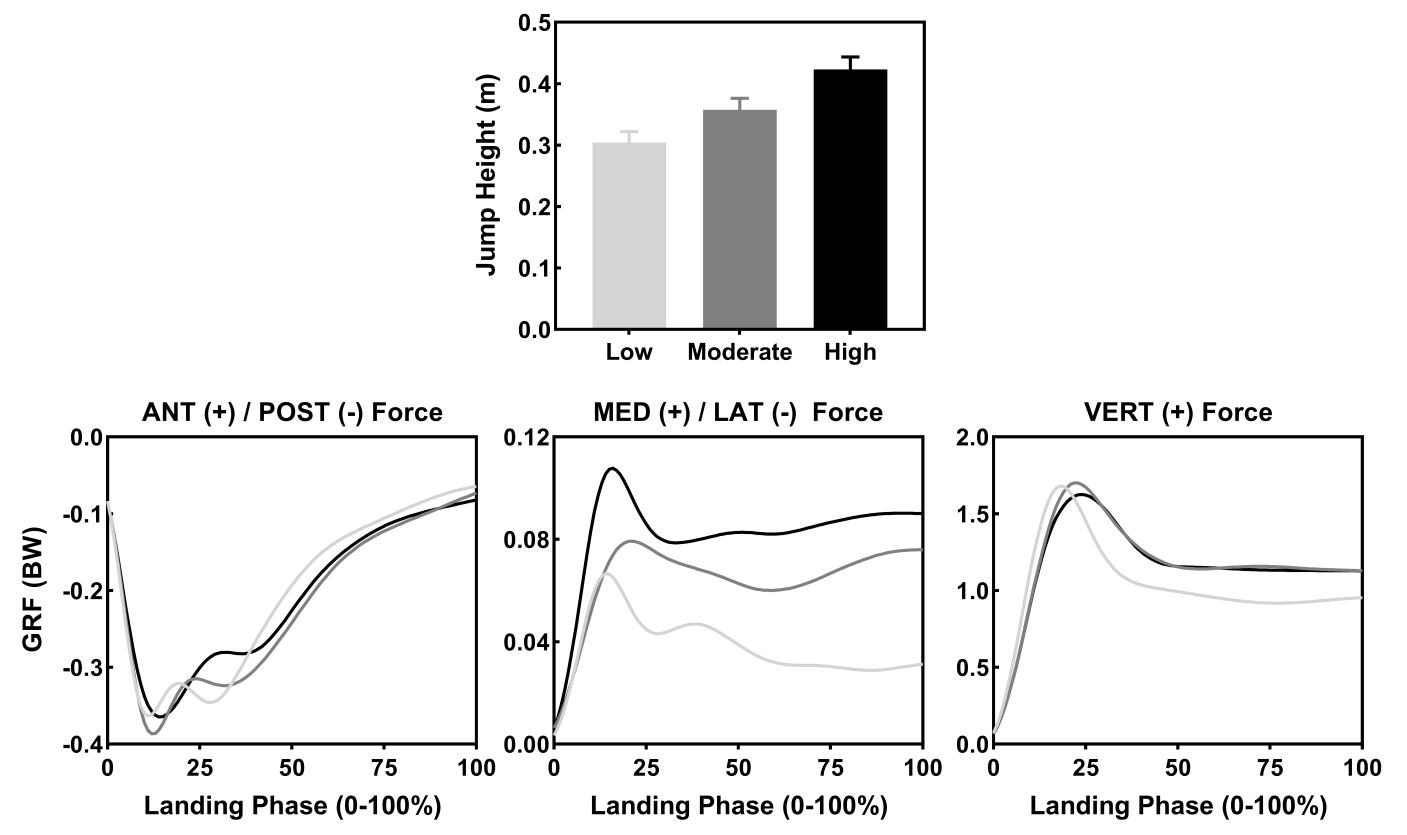

Figure 3: Mean ground reaction forces (GRF) across the landing phase for trials categorised as 'low' $(n=53)$, 'moderate' $(n=52)$ and 'high' $(n=55)$ performance based on jump height. ANT-anterior; POST-posterior; MED medial; LAT - lateral; VERT - vertical.

greater medial GRF at $86-89 \%(\mathrm{p}=0.001)$, and greater vertical GRF at $59-100 \%(\mathrm{p}<0.0001)$ of the landing phase were all associated with greater jump height (see Figure 3).

\subsection{Ground Contact Time}

Figures four, five and six show mean joint rotations, knee joint moments and GRF data, respectively, for trials categorised as 'low,' 'moderate' and 'high' performance based on ground contact time.

\subsubsection{Joint Rotations}

A statistically significant relationship was observed between ground contact time and 3D hip joint rotations at $18-100 \%(\mathrm{p}<0.0001)$ of the landing phase. Post-hoc analyses revealed statistically significant relationships between the sagittal-frontal hip joint rotation vector-field couple at $18-100 \%(\mathrm{p}<0.0001)$; the sagittaltransverse hip joint rotation vector-field cou- ple at $19-100 \%(\mathrm{p}<0.0001)$; and the frontaltransverse hip joint rotation vector-field couple at $76-86 \%(\mathrm{p}=0.0004)$ of the landing phase. Reduced hip flexion at $18-100 \%(\mathrm{p}<0.0001)$ and reduced hip internal rotation at $67-94 \%$ $(\mathrm{p}<0.0001)$ of the landing phase were associated with shorter ground contact times (see Figure 4). A statistically significant relationship was observed between ground contact time and 3D knee joint rotations at $10-100 \%$ $(\mathrm{p}<0.0001)$ of the landing phase. Post-hoc analyses revealed statistically significant relationships between the sagittal-frontal knee joint rotation vector-field couple at 9-100\% ( $\mathrm{p}<$ $0.0001)$; the sagittal-transverse knee joint rotation vector-field couple at $9-100 \%(\mathrm{p}<0.0001)$; and the frontal-transverse knee joint rotation vector-field couple at $66-93 \%(\mathrm{p}<0.0001)$ of the landing phase. Reduced knee flexion at $9-100 \%$ $(\mathrm{p}<0.0001)$ and greater knee abduction at 65$100 \%(p<0.0001)$ of the landing phase were associated with shorter ground contact times 

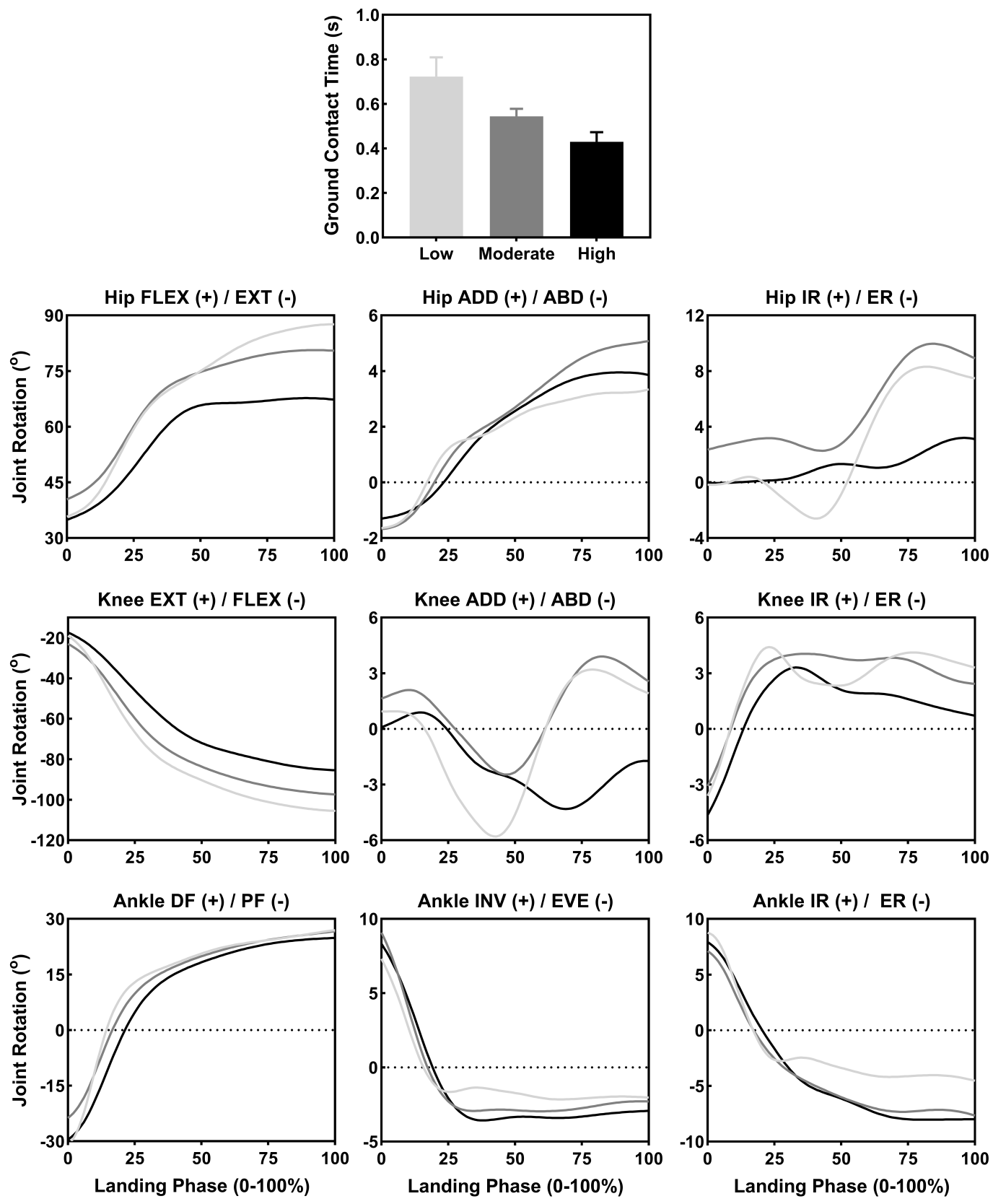

Figure 4: Mean hip, knee and ankle joint rotations across the landing phase for trials categorised as 'low' $(n=55)$, 'moderate' $(n=51)$ and 'high' $(n=54)$ performance based on ground contact time. FLEX - flexion; EXT - extension; $A D D$ - adduction; $A B D$ - abduction; IR - internal rotation; ER - external rotation; DF dorsiflexion; PF - plantarflexion; INV - inversion; EVE - eversion.

(see Figure 4). A statistically significant relationship was observed between ground contact time and 3D ankle joint rotations at 8-42\% (p < $0.0001)$ and $51-100 \%(\mathrm{p}<0.0001)$ of the landing 

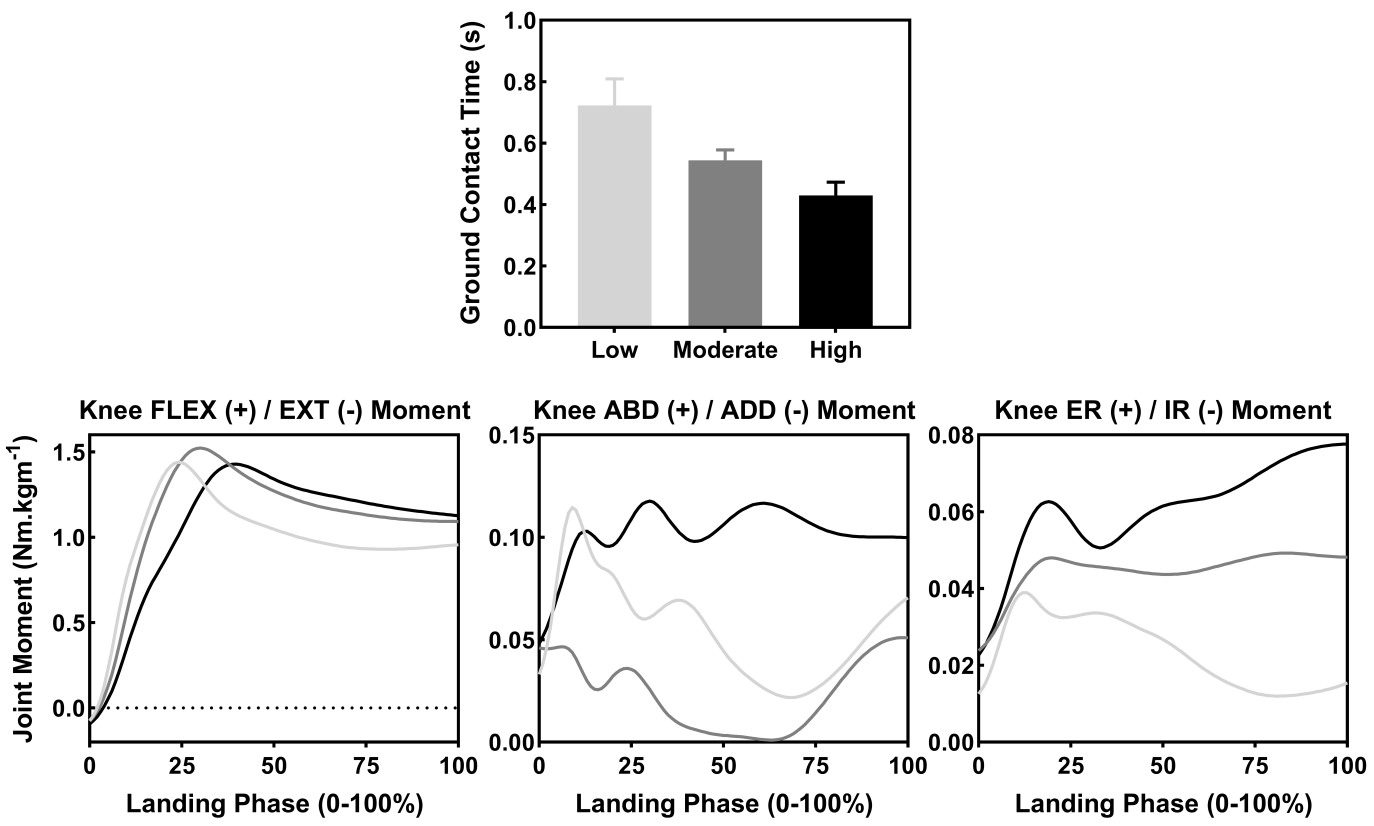

Figure 5: Mean knee joint moments across the landing phase for trials categorised as 'low' $(n=55)$, 'moderate' $(n=$ 51) and 'high' $(n=54)$ performance based on ground contact time. FLEX - flexion; EXT - extension; ADD - adduction; $A B D$ - abduction; IR - internal rotation; ER - external rotation.

phase. Post-hoc analyses revealed statistically significant relationships between the sagittalfrontal ankle joint rotation vector-field couple at $8-37 \%(\mathrm{p}<0.0001)$; the sagittal-transverse ankle joint rotation vector-field couple at $9-100 \%$ ( $\mathrm{p}<0.0001)$; and the frontal-transverse ankle joint rotation vector-field couple at $63-100 \%(\mathrm{p}$ $<0.0001)$ of the landing phase. Greater plantarflexion/reduced dorsiflexion at 9-35\% ( $\mathrm{p}=$ $0.0002)$ and greater ankle external rotation at $59-100 \%(p<0.0001)$ of the landing phase were associated with shorter ground contact times (see Figure 4).

\subsubsection{Knee Joint Moments}

A statistically significant relationship was observed between ground contact time and 3D knee joint moments at $2-27 \%(\mathrm{p}<0.0001)$ and $35-100 \%(\mathrm{p}<0.0001)$ of the landing phase. Posthoc analyses revealed statistically significant relationships between the sagittal-frontal knee joint moment vector-field couple at $2-26 \%$ ( $p$ $<0.0001)$ and $35-96 \%(\mathrm{p}<0.0001)$; the sagittaltransverse knee joint moment vector-field couple at $1-27 \%(\mathrm{p}<0.0001)$ and $35-100 \%(\mathrm{p}<$ 0.0001 ); and the frontal-transverse knee joint moment vector-field couple at $74-96 \%$ ( $\mathrm{p}=$ $0.0001)$ of the landing phase. Reduced knee flexion moments at $2-27 \%(\mathrm{p}<0.0001)$, greater knee flexion moments at 34-99\% ( $<<0.0001)$, and greater knee internal rotation moments at $69-100 \%$ ( $p<0.0001)$ of the landing phase were associated with shorter ground contact times (see Figure 5).

\subsubsection{Ground Reaction Forces (GRFs)}

A statistically significant relationship was observed between ground contact time and GRFs at $1-18 \%(\mathrm{p}<0.0001)$ and $21-100 \%(\mathrm{p}<0.0001)$ of the landing phase. Post-hoc analyses revealed statistically significant relationships between the anterior/posterior-medial/lateral 

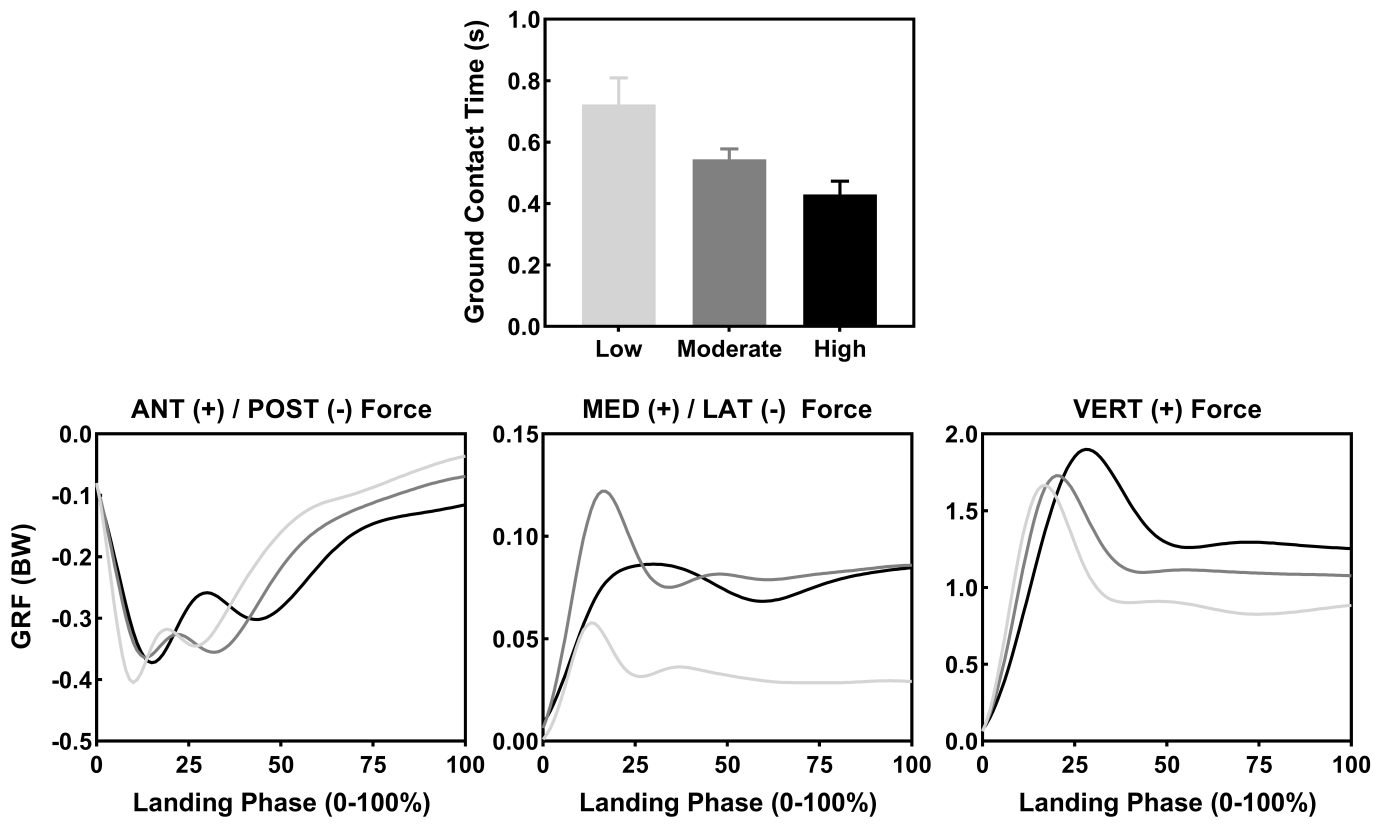

Figure 6: Mean ground reaction forces (GRF) across the landing phase for trials categorised as 'low' ( $n=55)$, 'moderate' $(n=51)$ and 'high' $(n=54)$ performance based on ground contact time. ANT-anterior; POST-posterior; MED - medial; LAT - lateral; VERT - vertical.

GRF vector-field couple at $2-10 \%(\mathrm{p}=0.0005)$, $25-31 \%(\mathrm{p}=0.0008)$ and $36-100 \%(\mathrm{p}<0.0001)$; the anterior/posterior-vertical GRF vector-field couple at $2-17 \%(\mathrm{p}=0.0004)$ and $22-100 \%(\mathrm{p}$ $<0.0001$ ); and the medial/lateral-vertical GRF vector-field couple at $1-17 \%(\mathrm{p}<0.0001)$ and $21-100 \%(\mathrm{p}<0.0001)$ of the landing phase. Reduced posterior GRF at 2-10\% ( $<<0.0001)$; and greater posterior GRF at $40-100 \%(\mathrm{p}<0.0001)$, greater medial GRF at $31-44 \%(\mathrm{p}=0.0001)$ and reduced vertical GRF at $2-17 \%(\mathrm{p}<0.0001)$ and greater vertical GRF at $22-100 \%(\mathrm{p}<0.0001)$ were all associated with shorter ground contact times (see Figure 6).

\subsection{Peak Power}

Figures seven, eight and nine show mean joint rotations, knee joint moments and GRF data, respectively, for trials categorised as 'low,' 'moderate' and 'high' performance based on peak power.

\subsubsection{Joint Rotations}

No statistically significant relationships were identified between peak power and hip or knee joint rotations. A statistically significant relationship was observed between peak power and 3D ankle joint rotations at $5-17 \%(\mathrm{p}=$ $0.0007)$ and $45-100 \%(\mathrm{p}<0.0001)$ of the landing phase. Post-hoc analyses revealed statistically significant relationships between the sagittaltransverse ankle joint rotation vector-field couple at $49-85 \%(\mathrm{p}<0.0001)$; and the frontaltransverse ankle joint rotation vector-field couple at $42-100 \%(\mathrm{p}<0.0001)$ of the landing phase. Greater ankle external rotation at $45-93 \%$ ( $\mathrm{p}<$ 0.0001) of the landing phase was associated with higher peak power (see Figure 7).

\subsubsection{Knee Joint Moments}

A statistically significant relationship was observed between peak power and 3D knee joint moments at $48-57 \%(\mathrm{p}=0.0007)$ of the landing 

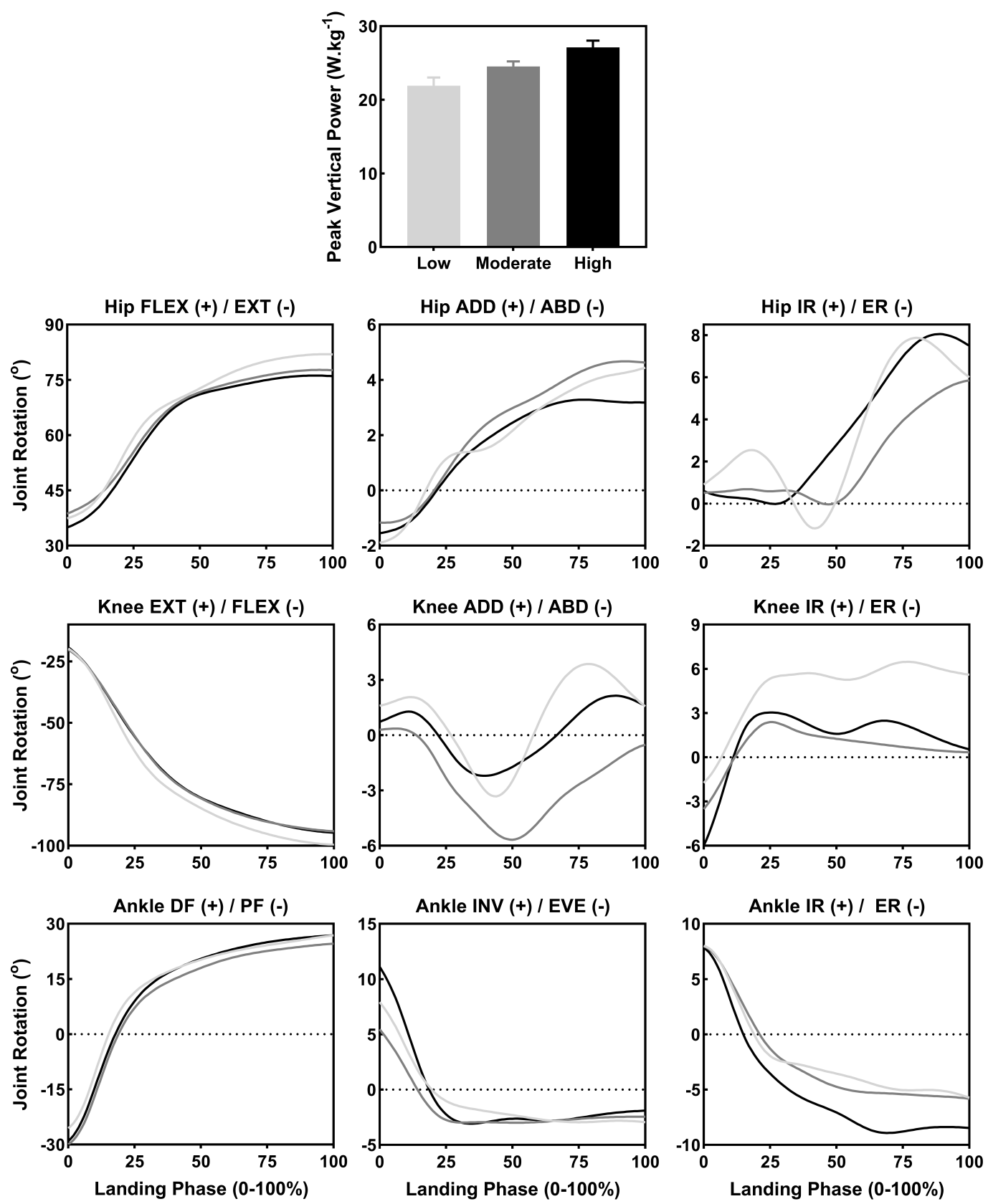

Figure 7: Mean hip, knee and ankle joint rotations across the landing phase for trials categorised as 'low' $(n=53)$, 'moderate' $(n=52)$ and 'high' $(n=55)$ performance based on peak vertical power. FLEX - flexion; EXT - extension; $A D D$ - adduction; $A B D$ - abduction; IR - internal rotation; ER - external rotation; DF dorsiflexion; PF - plantarflexion; INV - inversion; EVE - eversion.

phase. Post-hoc analyses revealed a statistically significant relationship between the sagittal- transverse knee joint moment vector-field couple at $46-64 \%(p=0.0002)$ of the landing phase. 

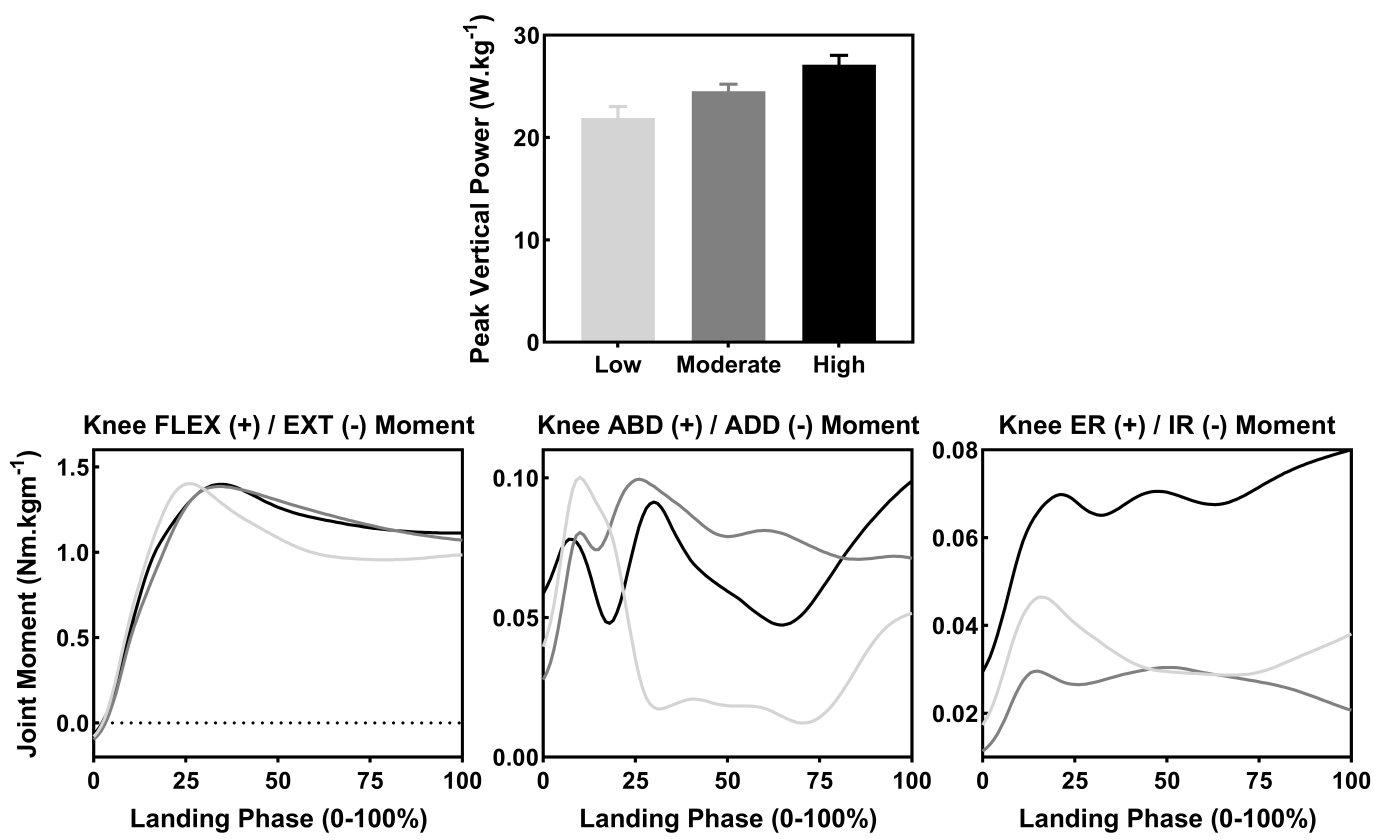

Figure 8: Mean knee joint moments across the landing phase for trials categorised as 'low' $(n=53)$, 'moderate' $(n=$ $52)$ and 'high' $(n=55)$ performance based on peak vertical power. FLEX - flexion; EXT-extension; ADD adduction; $A B D$ - abduction; IR - internal rotation; ER - external rotation.

No statistically significant relationships were identified between peak power and single knee joint moment components (see Figure 8).

\subsubsection{Ground Reaction Forces (GRFs)}

No statistically significant relationships were identified between peak power and GRFs (see Figure 9).

\section{Discussion}

This study examined whether there was a relationship between biomechanical factors associated with ACL loading or injury risk during landing and jump performance. A number of relationships between landing biomechanics and jump performance were identified. This is in line with existing research $[6$ and is not surprising given the task examined. The landing and jumping phases of the drop vertical jump task are inherently linked, as participants were required to complete the task in a fluid motion.
This action is similar to how athletes perform in sports where repetitive jump-landing manoeuvres are required. Given the links between landing technique and jumping performance, landing injury prevention and jump performance training should likely be considered in parallel. It is, however, important to examine the specific relationships to determine their importance in athlete training.

Combined frontal and transverse plane knee loading (i.e. abduction and internal rotation moments) results in the largest ACL loads [12, 13, 14, 15, 16]. The present study found a relationship between the frontaltransverse plane knee moment couple to jump height and ground contact time. Further posthoc analyses revealed that greater knee internal rotation moments during the landing phase were associated with greater jump height and shorter ground contact times. Participants displaying better jumping performance may 


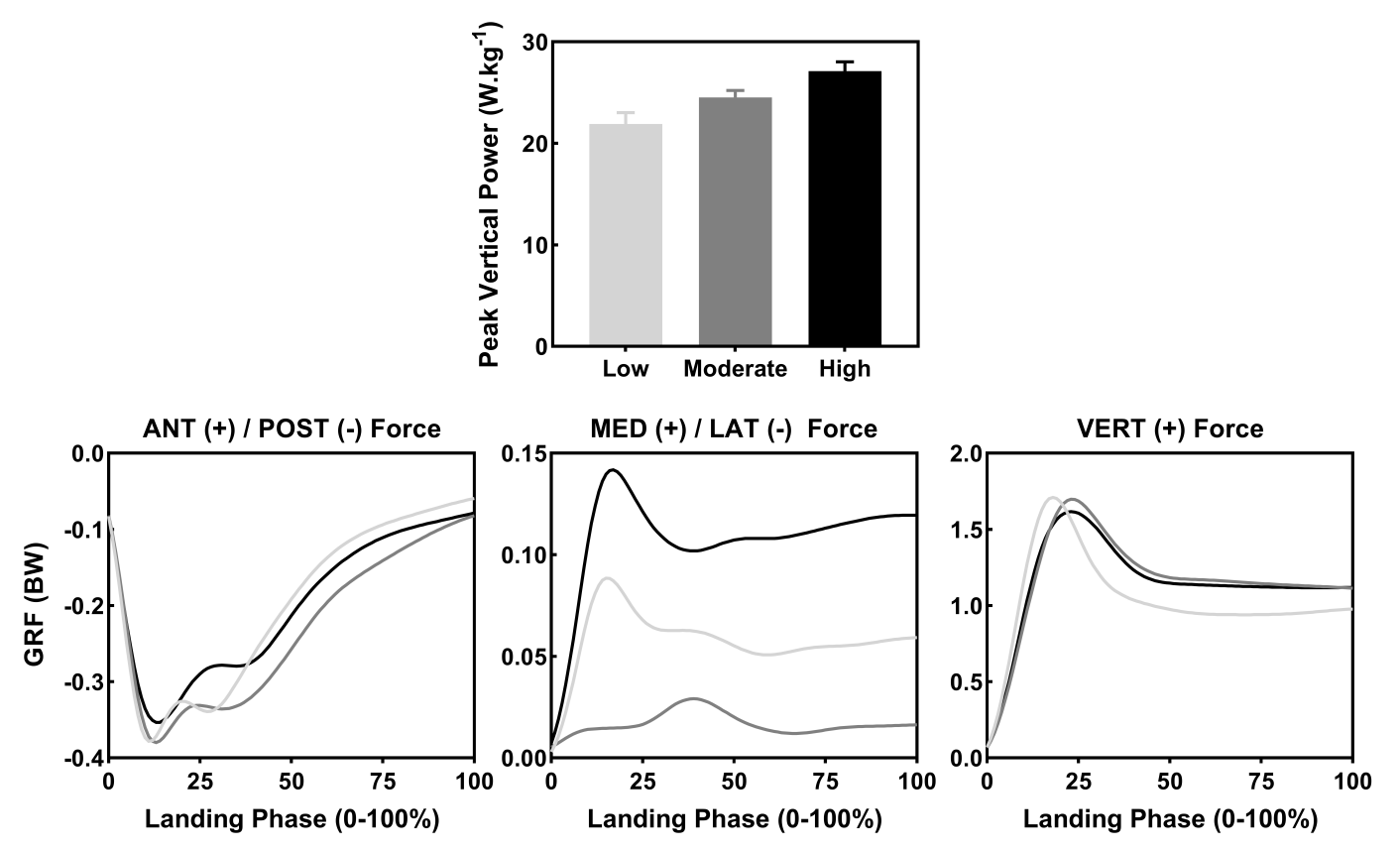

Figure 9: Mean ground reaction forces (GRF) across the landing phase for trials categorised as 'low' $(n=53)$, 'moderate' $(n=52)$ and 'high' $(n=55)$ performance based on peak vertical power. ANT-anterior; POST-posterior; MED - medial; LAT - lateral; VERT - vertical.

expose themselves to higher loads at the knee joint, potentially increasing their risk of ACL injury. A reaction to this finding may be to promote landing techniques that reduce the forces experienced during landing (i.e. to land 'softly'), subsequently reducing the knee loads experienced by the athlete. However, the present study found that higher ground reaction forces during landing were linked with greater jump heights. The likely mechanism behind this is that those achieving higher jumps were able to transfer the force and/or momentum from landing to the propulsive phase of the jump, resulting in better performance. These findings reflect those of Dai et al.[6], who observed that 'soft' landings resulted in reduced peak posterior ground reaction force and jump height. This highlights an important component in considering landing technique and jump performance training in parallel. Where injury prevention programs promote a technique that reduces landing forces, this should be supplemented with training targeting force production during jumping.

Hip and knee kinematics are also a common factor proposed to impact ACL loading or injury risk during landing. Increased hip and knee flexion, reduced hip adduction and internal rotation, and reduced knee abduction and internal rotation are suggested to reduce ACL injury risk[17, 18, 19]. No statistically significant relationships were identified between hip or knee kinematics and jump height or peak power, suggesting an athlete may be able to follow such technique guidelines without sacrificing these elements of jump performance. However, increased hip and knee flexion, and reduced knee abduction during landing were associated with longer ground contact times. In contrast, reduced hip internal rotation during landing was associated with shorter ground contact times. A longer ground contact time could be considered detrimental 
to performance in situations where an athlete is required to rapidly jump upon landing. Further, an increased time in contact with the ground may decouple the eccentric and concentric phases of the stretch-shortening cycle, reducing the maximum force produced in the subsequent movement|20]. This did not appear to be the case in the present study, as there was no relationship between increased hip or knee flexion and peak power output. Longer ground contact times with increased hip and knee flexion are not surprising, as there is an inherent requirement to increase the duration of the landing phase to reach larger hip and knee flexion angles. Instructing athletes to land in a flexed posture at initial contact, minimising the time required to achieve larger flexion angles, may be appropriate for achieving this protective landing strategy while also reducing ground contact time.

Ankle joint kinematics also appear to play a role in ACL loading and injury risk[21, 22, 23]. A more dorsiflexed ankle at initial landing contact (i.e. rearfoot landing) increases the load placed on the knee and ACL during dynamic tasks [21-23]. Further, ankle eversion is proposed to contribute to 'dynamic valgus,' [24] a posture linked with ACL injuries [25, 26]. Various associations between ankle joint kinematics and jump performance were identified. Greater ankle eversion during landing was associated with greater jump heights. The greater jumping performance observed with more ankle eversion is potentially concerning given the role it can play in producing 'dynamic valgus' postures. However, 'dynamic valgus' is a multi-joint and multi-planar concept, with hip adduction and knee abduction also contributing to produce the hazardous posture[24]. Considering frontal plane hip and knee kinematics were not associated with jump height and peak power, better jump performances characterised by greater ankle eversion in isolation are unlikely to contribute to a 'dynamic valgus' posture. Greater plantarflexion/reduced dorsiflexion early in the landing phase were associated with shorter ground contact times. This appears to demonstrate a positive link between safer landing technique and performance, whereby those shifting away from a rearfoot landing were able to transition to the jumping phase in a more rapid manner.

This study is not without limitations. A generic, predominantly sagittal plane bilateral jumplanding task was used. ACL injuries predominantly occur during unilateral sport-specific landing and cutting task[25, 26, 27], with these tasks likely incorporating a greater degree of frontal and transverse plane motion than a drop-vertical jump-landing. Changing the task demands to better resemble common ACL injury scenarios may alter the relationships between ACL injury risk and performance. It is important that future work explores more sport-specific scenarios. In addition, data was only taken from a single limb, assuming a degree of symmetry between limbs during the task. It is possible that athletes may display a variable relationship between limbs for potential ACL injury risk and jump performance, if they display an asymmetrical jump-landing pattern.

\section{Conclusion}

A number of relationships between landing biomechanics and jump performance were identified. Biomechanical factors that may be targeted within landing injury prevention programs were associated with both poorer and better jump performance. The relationships identified in this study suggest where a greater jump height is desired, instructing athletes to landing with reduced ground reaction forces (i.e. 'softly') may be detrimental to jumping performance. Conversely, where a shorter ground contact time leading into a jump is desired, instructing athletes to land with greater hip and knee flexion, and reduced knee abduction may be detrimental to jumping performance. Jump performance training should be considered in parallel with ACL injury prevention programs incorporating landing technique guidelines, particularly in sports where 
frequent jump-landing tasks are performed.

\section{References}

[1] Fox AS, Spittle M, Otago L, Saunders N. Descriptive analysis of landings during international netball competition: Enhancing ecological validity of laboratory testing environments. International Journal of Performance Analysis in Sport. 2013 dec;13(3):690-702. Available from: https: //www . tandfonline.com/doi/full/10. 1080/24748668.2013.11868681.

[2] Skazalski C, Whiteley R, Bahr R. High jump demands in professional volleyballlarge variability exists between players and player positions. Scandinavian Journal of Medicine \& Science in Sports. 2018 nov;28(11):2293-2298. Available from: http://doi.wiley.com/10.1111/ sms.13255

[3] Hewett TE, Ford KR, Myer GD. Anterior cruciate ligament injuries in female athletes: Part 2, a meta-analysis of neuromuscular interventions aimed at injury prevention. The American journal of sports medicine. 2006 mar;34(3):490-8. Available from: http://journals.sagepub.com/ doi/10.1177/0363546505282619http: //www.ncbi.nlm.nih.gov/pubmed/ 16423913http://www.ncbi.nlm.nih. gov/pubmed/16382007

[4] Mandelbaum BR, Silvers HJ, Watanabe DS, Knarr JF, Thomas SD, Griffin LY, et al. Effectiveness of a Neuromuscular and Proprioceptive Training Program in Preventing Anterior Cruciate Ligament Injuries in Female Athletes. The American Journal of Sports Medicine. 2005 jul;33(7):1003-1010. Available from: http://journals.sagepub. com/doi/10.1177/0363546504272261.

[5] Myklebust G, Engebretsen L, Brækken $\mathrm{IH}$, Skjølberg A, Olsen OE, Bahr R. Prevention of Anterior Cruciate Ligament Injuries in Female Team
Handball Players: A Prospective Intervention Study Over Three Seasons. Clinical Journal of Sport Medicine. 2003 mar;13(2):71-78. Available from: https://insights.ovid.com/crossref? an=00042752-200303000-00002.

[6] Dai B, Garrett WE, Gross MT, Padua DA, Queen RM, Yu B. The Effects of 2 Landing Techniques on Knee Kinematics, Kinetics, and Performance During Stop-Jump and Side-Cutting Tasks. The American Journal of Sports Medicine. 2015 feb;43(2):466-474. Available from: http://journals.sagepub. com/doi/10.1177/0363546514555322.

[7] Vescovi JD, VanHeest JL. Effects of an anterior cruciate ligament injury prevention program on performance in adolescent female soccer players. Scandinavian Journal of Medicine \& Science in Sports. 2009 jun;20(3):394-402. Available from: http://doi.wiley.com/10.1111/ j.1600-0838.2009.00963.x.

[8] Padua DA, Marshall SW, Boling MC, Thigpen CA, Garrett WE, Beutler AI. The Landing Error Scoring System (LESS) Is a Valid and Reliable Clinical Assessment Tool of Jump-Landing Biomechanics. The American Journal of Sports Medicine. 2009 oct;37(10):1996-2002. Available from: http://journals.sagepub.com/ doi/10.1177/0363546509343200

[9] McLean SG, Samorezov JE. Fatigueinduced ACL injury risk stems from a degradation in central control. Medicine and science in sports and exercise. 2009 aug;41(8):1661-72. Available from: https: //insights.ovid.com/crossref?an= 00005768-200908000-00017http://www . ncbi.nlm.nih.gov/pubmed/19568192.

[10] Kristianslund E, Krosshaug T, Mok KM, McLean S, van den Bogert AJ. Expressing the joint moments of drop jumps and sidestep cutting in different reference frames - does it matter? Journal of 
Biomechanics. 2014 jan;47(1):193-199. Available from: http://dx.doi.org/10. 1016/j.jbiomech.2013.09.016https: //linkinghub.elsevier.com/retrieve/ pii/S0021929013004399

[11] Pataky TC, Robinson MA, Vanrenterghem J. Vector field statistical analysis of kinematic and force trajectories. Journal of Biomechanics. 2013 sep;46(14):2394-2401. Available from: http://dx.doi.org/10. 1016/j.jbiomech.2013.07.031https: //linkinghub.elsevier.com/retrieve/ pii/S0021929013003564.

[12] Kiapour AM, Kiapour A, Goel VK, Quatman CE, Wordeman SC, Hewett $\mathrm{TE}$, et al. Uni-directional coupling between tibiofemoral frontal and axial plane rotation supports valgus collapse mechanism of ACL injury. Journal of Biomechanics. 2015 jul;48(10):1745-1751. Available from: http://dx.doi.org/10. 1016/j.jbiomech.2015.05.017https: //linkinghub.elsevier.com/retrieve/ pii/S0021929015002948

[13] Kiapour AM, Demetropoulos CK, Kiapour A, Quatman CE, Wordeman SC, Goel VK, et al. Strain Response of the Anterior Cruciate Ligament to Uniplanar and Multiplanar Loads During Simulated Landings. The American Journal of Sports Medicine. 2016 aug;44(8):2087-2096. Available from: http://journals.sagepub. com/doi/10.1177/0363546516640499

[14] Shin CS, Chaudhari AM, Andriacchi TP. Valgus plus internal rotation moments increase anterior cruciate ligament strain more than either alone. Medicine and science in sports and exercise. 2011 aug;43(8):1484-91. Available from: https: //insights.ovid.com/crossref?an= 00005768-201108000-00013http://www. ncbi.nlm.nih.gov/pubmed/21266934

[15] Quatman CE, Kiapour AM, Demetropoulos CK, Kiapour A, Wordeman SC, Levine JW, et al. Preferential Loading of the
ACL Compared With the MCL During Landing. The American Journal of Sports Medicine. 2014 jan;42(1):177-186. Available from: http://journals.sagepub. com/doi/10.1177/0363546513506558.

[16] Oh YK, Lipps DB, Ashton-Miller JA, Wojtys EM. What Strains the Anterior Cruciate Ligament During a Pivot Landing? The American Journal of Sports Medicine. 2012 mar;40(3):574-583. Available from: http://journals.sagepub. com/doi/10.1177/0363546511432544.

[17] Shultz SJ, Schmitz RJ, Benjaminse A, Collins M, Ford K, Kulas AS. ACL Research Retreat VII: An Update on Anterior Cruciate Ligament Injury Risk Factor Identification, Screening, and Prevention. Journal of Athletic Training. 2015 oct;50(10):1076-1093. Available from: http://natajournals.org/ doi/10.4085/1062-6050-50.10.06.

[18] Hewett TE, Myer GD, Ford KR. Anterior cruciate ligament injuries in female athletes: Part 1, mechanisms and risk factors. The American journal of sports medicine. 2006 feb;34(2):299-311. Available from: http://journals.sagepub.com/doi/ 10.1177/0363546505284183http://www . ncbi.nlm.nih.gov/pubmed/16423913

[19] Griffin LY, Agel J, Albohm MJ, Arendt EA, Dick RW, Garrett WE, et al. Noncontact anterior cruciate ligament injuries: risk factors and prevention strategies. The Journal of the American Academy of Orthopaedic Surgeons. 2000;8(3):141-50. Available from: http://www.ncbi.nlm. nih.gov/pubmed/10874221.

[20] Kobsar D, Barden J. Contact Time Predicts Coupling Time in Slow StretchShortening Cycle Jumps. Journal of Strength and Conditioning Research. 2011 mar;25:S51-52. Available from: http://insights.ovid.com/crossref? $\mathrm{an}=00124278-201103001-00079$ 
[21] Donnelly CJ, Chinnasee C, Weir G, Sasimontonkul S, Alderson J. Joint dynamics of rear- and fore-foot unplanned sidestepping. Journal of Science and Medicine in Sport. 2017 jan;20(1):32-37. Available from: http://dx.doi.org/ 10.1016/j.jsams.2016.06.002https: //linkinghub.elsevier.com/retrieve/ pii/S1440244016301074

[22] Kristianslund E, Faul O, Bahr R, Myklebust G, Krosshaug T. Sidestep cutting technique and knee abduction loading: implications for ACL prevention exercises. British Journal of Sports Medicine. 2014 may;48(9):779-783. Available from: http://bjsm.bmj.com/lookup/ doi/10.1136/bjsports-2012-091370

[23] Yoshida N, Kunugi S, Mashimo S, Okuma Y, Masunari A, Miyazaki S, et al. Effect of Forefoot Strike on Lower Extremity Muscle Activity and Knee Joint Angle During Cutting in Female Team Handball Players. Sports Medicine - Open. 2016 dec;2(1):32. Available from: http://dx.doi.org/ 10.1186/s40798-016-0056-xhttp: //sportsmedicine-open. springeropen.com/articles/10.1186/ s40798-016-0056-x

[24] Hewett TE, Myer GD, Ford KR, Heidt RS, Colosimo AJ, McLean SG, et al. Biomechanical Measures of Neuromuscular Control and Valgus Loading of the Knee Predict Anterior Cruciate Ligament Injury
Risk in Female Athletes: A Prospective Study. The American Journal of Sports Medicine. 2005 apr;33(4):492-501. Available from: http://journals.sagepub com/doi/10.1177/0363546504269591.

[25] Olsen OE, Myklebust G, Engebretsen L, Bahr R. Injury mechanisms for anterior cruciate ligament injuries in team handball: a systematic video analysis. The American journal of sports medicine. 2004 jun;32(4):1002-12. Available from: http://journals.sagepub.com/doi/ 10.1177/0363546503261724http://www . ncbi.nlm.nih.gov/pubmed/15150050.

[26] Krosshaug T, Nakamae A, Boden BP, Engebretsen L, Smith G, Slauterbeck JR, et al. Mechanisms of anterior cruciate ligament injury in basketball: video analysis of 39 cases. The American journal of sports medicine. 2007 mar;35(3):359-67. Available from: http://journals.sagepub.com/doi/ 10.1177/0363546506293899http://www. ncbi.nlm.nih.gov/pubmed/17092928.

[27] Stuelcken MC, Mellifont DB, Gorman AD, Sayers MGL. Mechanisms of anterior cruciate ligament injuries in elite women's netball: a systematic video analysis. Journal of sports sciences. 2016 aug;34(16):1516-22. Available from: http://www.ncbi.nlm.nih. gov/pubmed/26644060. 